\title{
Study on the Bilingual Teaching of International Economics-Based on the Model of Outcome-Based Education
}

\author{
Hui Jia, Yongping Jing* \\ School of Economics and Management, Beijing Institute of Petrochemical Technology, Beijing, China \\ Email: *jingyongping@yeah.net
}

How to cite this paper: Jia, H., \& Jing, Y. P. (2020). Study on the Bilingual Teaching of International Economics-Based on the Model of Outcome-Based Education. Creative Education, 11, 1407-1417. https://doi.org/10.4236/ce.2020.118103

Received: August 1, 2020

Accepted: August 24, 2020

Published: August 27, 2020

Copyright (๑) 2020 by author(s) and Scientific Research Publishing Inc. This work is licensed under the Creative Commons Attribution International License (CC BY 4.0).

http://creativecommons.org/licenses/by/4.0/

\section{(c) (i) Open Access}

\begin{abstract}
The Outcome-based Education (OBE) emphasizes outcome orientation, student-centered education and continuous improvement. It is considered the direction of excellence in education, and its core value lies in the introduction of a new quality culture for talents cultivation. Based on the teaching practice of International Economics, this paper studies the specific application of the OBE teaching philosophy according to the demand of social and economic development for internationalized and application-oriented talents. Based on the analysis of the current problems in bilingual teaching, some countermeasures are put forward from the course objectives and outcomes, design of teaching process, design of evaluation system and construction of bilingual learning resources. It aims to establish an operational and replicable model for student-centered teaching and outcome-based learning, as well as cultivating application-oriented talents in the field of international business and economics.
\end{abstract}

\section{Keywords}

OBE, Bilingual Teaching, Course Objectives, Teaching Process, Evaluation

\section{Introduction}

Cultivating internationalized and application-oriented talents is the objective need for universities to adapt to the development of global economy and society, and an inevitable choice for the popularization of higher education. The Outcome-based Education (OBE) was proposed by American scholar Spady in 1981. In terms of course teaching, its main connotation can be summarized as "outcome-based", "student-centered" and "continuous improvement". On the pro- 
fessional level, it is required to establish a talents cultivating mechanism that meets the needs of learners' development and social needs. The OBE has formed a complete theoretical system, guiding many successful practices, and is regarded as the direction of excellence in education. This concept is of great significance and far-reaching influence, and its core value lies in the introduction of a new quality culture for education.

As a basic discipline of economics, International Economics is based on the research methods of Microeconomics and Macroeconomics, and has a relatively large curriculum system, supported by other specialized courses, and has higher requirement for mathematical ability. In order to further expand students' international vision, many Chinese colleges and universities use the original English textbooks and adopt bilingual teaching in both Chinese and English, aiming to guide students to analyze and solve practical problems with the basic theories and methods of International Economics, and to cultivate their thinking, judgment and English communication skills required for foreign business work.

Based on the teaching practice of International Economics, this paper studies the specific application of the OBE philosophy according to the demand of social and economic development for internationalized and application-oriented talents. Based on the analysis of the current problems in bilingual teaching, some countermeasures are put forward from the course objectives and outcomes, design of teaching process, design of the evaluation system and construction of bilingual learning resources. It aims to establish an operational and replicable model for student-centered teaching and outcome-based learning, as well as cultivating application-oriented talents in the field of international business and economics.

\section{Literature Review}

\subsection{International Research Status}

The research on the Outcome-based Education (OBE) is systematic and comprehensive internationally, including expounding its concept and contents, reviewing its evolution process and results, constructing theoretical models, analyzing the key points of implementation, evaluating the implementation effects, and applying it to the practice of teaching reforms. The OBE was proposed by American scholar Spady in 1981, namely, "clearly focus and organize the education system to ensure that students can get successful experiences in future life". Based on this, Acharya put forward the basic principles of the OBE, including direction design, expanding opportunities, setting high expectations and giving support for success, and clear focus of outcomes. Harden and Crosby conducted a much thorough study on the outcome model, and they proposed the Dundee Three-Circle model (Amini, 2014). In the field of practice, Battistini (1995) studied the application of OBE in the classroom, and pointed out that although its implementation involved groups, the most critical task and role in the classroom 
was the teacher. Learning (2010) studied objects of the education implementation in Hong Kong and found that practices, policies and theories interact with each other and can act together on the implementation of outcome-based education.

The implementation of the OBE has created different curriculum model with different characteristics over the years. The first is the Recognition Standard EC2000 and the Engineering Curriculum Program, jointly launched in 1995 by the Accreditation Organization for Engineering and Technical Education (ABET). This model emphasizes the learning outcomes and requires that graduates must have the knowledge to maintain survivability. The second is the development model of the medical curriculum, which emphasizes that the educational process must follow six development steps, namely, student needs assessment, implementation goals, problem identification, educational strategies, evaluation and feedback. Thirdly is the continuous improvement evaluation model: Rogers proposed the importance and necessity of implementing continuous improvement evaluation mechanism in higher education institutions (Zambrano, 2020). Finally, it is the adjustment model, which emphasizes the identification of resources and needs, defining graduation requirements, construction of curriculums, determination of evaluation types, defining capability outcomes, evaluation and improvement.

On the whole, internationally theoretical and practical studies are systematic and comprehensive, which lays a good foundation for Chinese scholars to correctly understand the OBE and carry out teaching reform studies combining the characteristics of Chinese practice.

\subsection{Research Status in China and Application in Chinese Universities}

The earliest research on the Outcome-based Education (OBE) in China started in 2003. Jiang (2003) structured the "Outcome-based Education System". Li (2014) proposed that the implementation of the OBE must first change the teaching philosophy. Since then, more scholars have tried to apply it to the practice of the teaching reform. The OBE highlights the "student-centered" and "outcome-based "philosophy, which has set off an upsurge of research and practice in Chinese universities (Wang et al., 2017; Yang et al., 2019; Wang, 2020).

Education quality assurance has become a major issue for China's higher education. The Outline of the National Medium - and Long-term Plan for Education Reform and Development (2010-2020) states that improving the quality of education is the core task of higher education development and the basic requirement of building a powerful country in higher education. The outline also points out that a scientific concept of quality should be established and the promotion of people's integrated development and adaptation to social needs should be taken as the fundamental standard for measuring the quality of education ( $\mathrm{Wu}, 2011)$. With the progress of economy and society, China's higher education has made great progress, and has entered the "popularization stage of 
higher education" since 1999. Although "more is not necessarily worse", the reality has shown that the popularization of higher education has brought about a decline in the quality of talents cultivation. Some are beginning to worry about whether the quality of teaching can maintain and improve the quality of talents. The evaluation results of the OBE can truly reflect the overall level of teaching and help to improve the teaching quality, which is also the fundamental mission of student evaluation of teaching.

However, there are few studies on the application of the OBE model in bilingual curriculum teaching. It is necessary to conduct systematic and comprehensive research, improve and perfect the corresponding teaching system and methods, and promote the realization of the goal of internationalized talents cultivation in colleges and universities.

\section{Problems in Bilingual Teaching Practice}

International economic relations between countries and regions are increasingly globalized. The status of International Economics has also been constantly improved, and has become a core course for all majors of economics. Therefore, exploring the teaching reform of International Economics is of great significance to improve the teaching quality and enhance students' ability to analyze and solve international economic problems with professional knowledge.

In order to further broaden students' international horizon, many Chinese universities have adopted bilingual teaching in International Economics, namely, using the original English textbooks and teaching in both Chinese and English. The main forms of teaching include flipped classroom, discussion-based teaching and case-based teaching. It conforms to the law of bilingual teaching, which plays an important role in cultivating students' foreign business competence. However, there are still some problems in practice, such as students' weak ability in applying theories and methods to practical analysis, the teaching method is traditional and the quality of teaching needs to be improved, which are mainly reflected in:

Firstly, the learning model is mostly "process-oriented", not "outcome-based". Students are the masters of the classroom and also one of the main characters of the teaching activities. To improve teaching efficiency, students must clearly expect learning outcomes. "Expected outcomes" should be defined as the starting point of teaching, on this basis, students should be guided to independently construct knowledge structure, acquire scientific and efficient learning methods, form strong learning ability, and promote the harmonious development of comprehensive literacy. However, the current situation is that students learn the "concept-theory-method-problem" step by step, and the learning model is "process-oriented" rather than "outcome-based". The result is that although students can better grasp the theoretical elements, the ability to analyze and solve practical economic and trade problems is weak, the ability to apply what they have learned to practices needs to be improved. 
Secondly, the selection of teaching contents and the design of teaching activities have not fully reflected the outcome-orientation. At present, it is relatively lack to select, reconstruct and refine the teaching contents of bilingual courses based on the target outcomes. Meanwhile, in view of the increasing attention to students' practical application ability, the teaching should take the expected outcomes as the starting point and the end point, strengthen the outcome orientation in the teaching process, and conduct a series of teaching activities around the target outcome.

Thirdly, the evaluation system is deficient. The current evaluation system lays particular stress on "knowledge-type outcomes" while the evaluation of "technique-type outcomes" and "competence-type outcomes" is relatively small. The elements of evaluation are not comprehensive and targeted.

Fourthly, bilingual learning resources are limited. Due to the differences of domestic and foreign teaching systems, institutional cultures and thinking modes, the original English teaching materials do not completely match the economic and social reality of China and students' English ability. Therefore, it is necessary to reform and design the teaching contents and supplement and improve the supporting teaching resources.

\section{Teaching Reform Based on the OBE Model}

The introduction of the OBE into bilingual teaching can realize the fundamental transformation of talents cultivation from "theoretical knowledge oriented" to "comprehensive ability oriented". Combined with the Three-stage Flipped Class Mode (before, during and after class) (refer to Ms. Kong Xinkai's lecture at the third Engineering Ethics Training Course, Hangzhou, July 22, 2020), the bilingual teaching process under the OBE is considered from the following aspects:

\subsection{Design Expected Learning Outcomes}

Determining expected learning outcomes is a basic step in the implementation of the OBE model, and it is also a crucial step. Taking International Economics as an example, teachers should deeply analyze the supporting function of this course to the graduation requirements of the major, and reversely design the
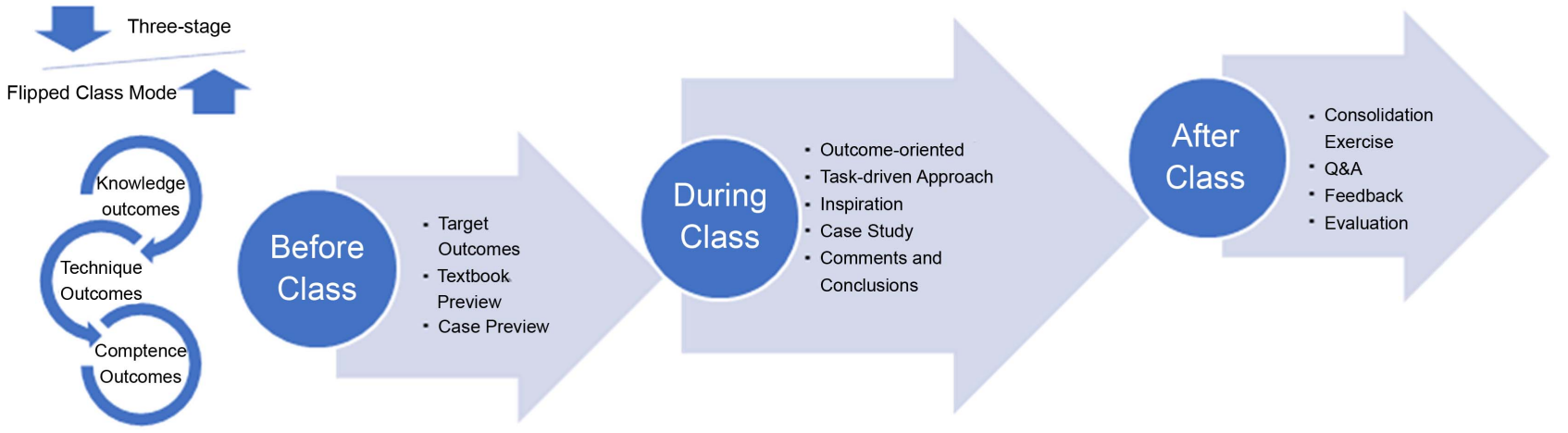

Figure 1. Three-stage flipped class mode based on the OBE. 
course objectives according to the graduation requirements, which should run through the whole process of "Three-stage Flipped Class Mode" (before, during and after class) (Figure 1). Teachers should divide learning outcomes into knowledge outcomes, technique outcomes and competence outcomes. Knowledge outcomes refer to the degree to which students master basic theoretical knowledge related to the major. Technique outcomes refer to students' proficiency in using analytical methods and tools. Competence outcomes refer to the ability of students to acquire knowledge and apply techniques proficiently after studying International Economics. Reasonable determination of learning outcomes enables students to improve their awareness of autonomous learning, and fully grasp the skills needed for social development. Through the comparison of the social demand for students' professional ability and students' basic situation, it is found that under the traditional teaching mode, students have a full grasp of theoretical knowledge, but lack certain ability in dealing with practical problems. At present, social development attaches great importance to the practical ability of students, and the requirements are also very strict. According to the social needs and the current situation of students, the OBE model is proposed to carry out with learning outcomes as the goal.

Teachers should set corresponding knowledge objectives, technique objectives and competence objectives for the cultivation of international talents. Knowledge objectives refer to the practical process of applying theoretical knowledge to the analysis of international economic issues. The realization of the objective requires teachers to combine some international cases or phenomena when explaining professional knowledge, so that the abstract theoretical knowledge can be easily understood and mastered. Technique objectives refer to the technical ability in the process of international practices, namely, the practical ability of applying models and analytical tools. In the course of teaching International Economics, international case study is indispensable. When exposed to English case data, materials or videos, teachers should help students sort out knowledge, explain key issues that should be paid attention to in the use of models and analyzing tools, and discuss problems encountered by students timely, so as to cultivate students' rigorous and pragmatic spirit, and improve their practical skills and language ability in English. Competence objectives refer to the ability to analyze and solve problems creatively when encountering problems related to the international economy. Through international economic cases, students can freely discuss, debate, report, make presentations, so as to cultivate their ability to analyze and solve practical problems independently.

\subsection{Design Teaching Contents and Activities}

Firstly, teachers should properly select teaching contents according to the target objectives, grasp the depth and breadth, and conduct module segmentation on the selected contents closely related to the target outcomes. In order to stimulate interests, guide discussions and inspire thinking, teachers need to introduce se- 
minars and inquiry teaching methods, and need to reconstruct the teaching contents by cases and projects. The bilingual course of international economics, designed according to the outcome-oriented principle, should not only reflect the applied professional knowledge of international trade, international finance and international factors flow, but also emphasize on improving students' ability to use English learning knowledge. It includes basic theories, methods and analytical tools, and focuses on cutting-edge knowledge and practical application.

Secondly, focusing on the target objectives and expected learning outcomes, the Three-stage Teaching Activities Based on the OBE is designed (Figure 2) to explore the formation of a teaching model that is integrated "before", "during" and "after" class, and involves diversified reforms of teaching forms, methods, resources, etc. Adhere to the outcome-based approach, make sufficient teaching plan before class, including case design and contents design, apply micro-lectures and MOOCS to students, assist them to conduct pre-class independent learning, and record and monitor their learning process through the teaching platform, so as to help students "get to know" the course contents before the class. In the classroom or online teaching process, teachers adhere to student-centered approach, conduct case studies, supplemented by inspirations and guidance, value student discussions and demonstrations and giving timely feedback. After class, teachers assign homework and quiz, summarize and adjust in time. Teachers should pay attention to students' "knowledge consolidation and communication innovation".

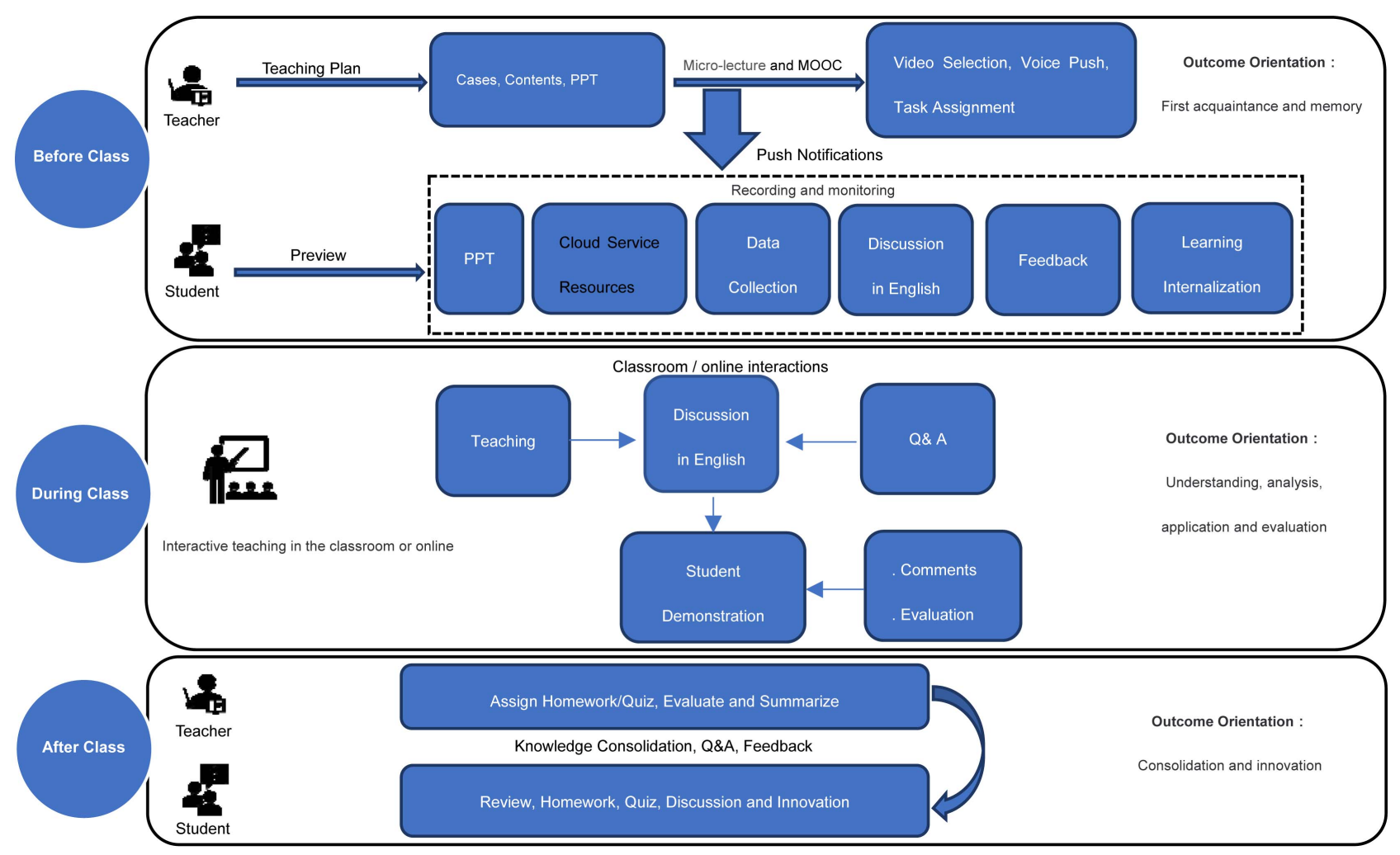

Figure 2. Three-stage teaching activities based on the OBE. 
Thirdly, based on the teaching theme and learner characteristics of International Economics, the Three-stage Teaching Network Based on the OBE (Figure 3 ) is designed to pursue teaching objectives and expected learning outcomes. It realizes the seamless connection and repeated mixing of "teaching and learning" activities before, during and after class. "Key and difficult knowledge analysis", "immersive case study" and "feedback and outcomes evaluation" run through the entire teaching network. Meanwhile, teachers should analyze the difficulties affecting the achievement of the target, design the way to achieve, including determining the key teaching links, design and timely adjust the teaching forms, teaching methods and tools of each link. Whether in case study, group presentation, role play or simulation exercise, students are required to actively use professional English vocabulary to ask questions, debate and communicate, which can help create a scene for students to communicate and solve problems in English. It is necessary to strengthen students' language application ability, and pay attention to the two-way infiltration of English and professional knowledge and the cultivation of English thinking, so that students can improve their professional knowledge and English application ability at the same time.

\subsection{Design the Outcome Assessment and the Teaching Evaluation System}

The outcome assessment is not only an important step to measure teaching quality, but also a key link to measure the rationality of teaching contents and
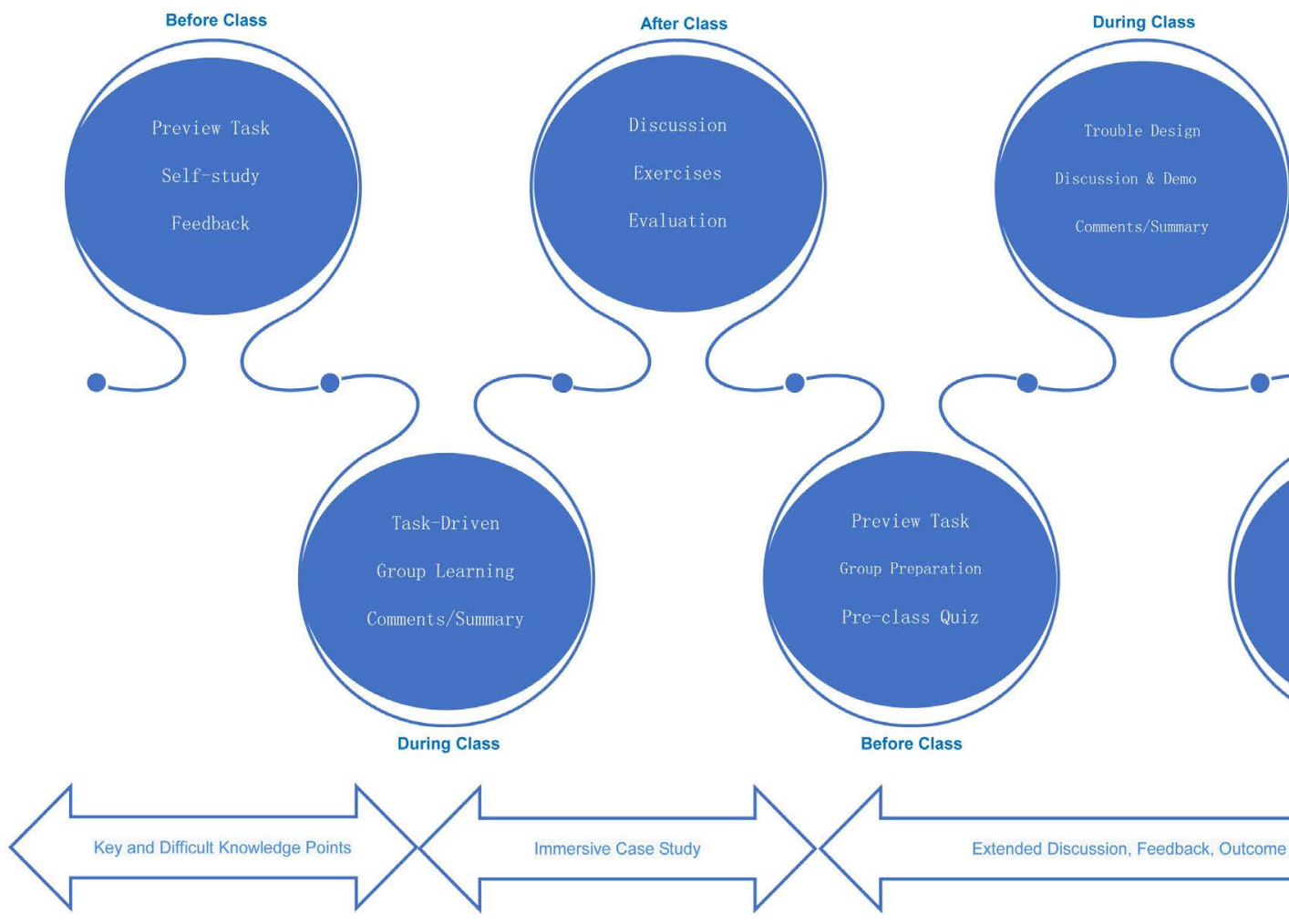

Before Class

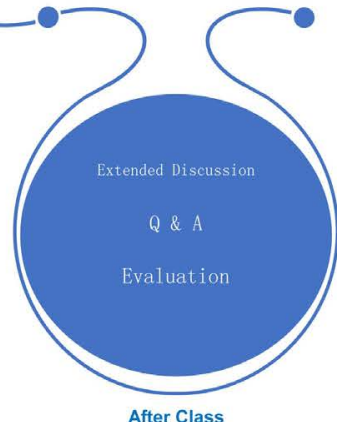

Figure 3. Three-stage teaching network based on the OBE. 
methods. Establishing a reasonable assessment system is an essential condition to achieve the expected learning outcomes. The OBE pedagogical assessment system focuses on learning outcomes rather than contents. According to various evaluation criteria and the degree of completion of education requirements, each student can be given a different rating, and can be evaluated in a targeted way. Based on this, the outcomes assessment plan under the OBE was constructed (Figure 4-Outcomes Assessment), and the process assessment (50\%) was combined with the final assessment (50\%). The process evaluation can be used to stimulate students' process learning and gradually promote the realization of the expected goal through the process assessment and formative evaluation. Final exam can be used to determine whether a student has achieved the expected learning outcomes. The assessment system covers the knowledge outcomes assessment, technique outcomes assessment and competence outcomes assessment. The assessment of knowledge outcomes evaluates students' mastery of professional knowledge through quiz, Q\&A and assignments. The technique outcomes assessment evaluates students' proficiency in the application of models, research methods and analysis tools through the processing, analysis and discussion of international economic data. The competence assessment is mainly based on international economic case study or project analysis, English report writing, English speech and defense. The final exam is a comprehensive outcome assessment of knowledge, techniques and competence, and the achievement of the corresponding outcomes is calculated respectively.

The outcomes assessment system should be integrated into a complete teaching

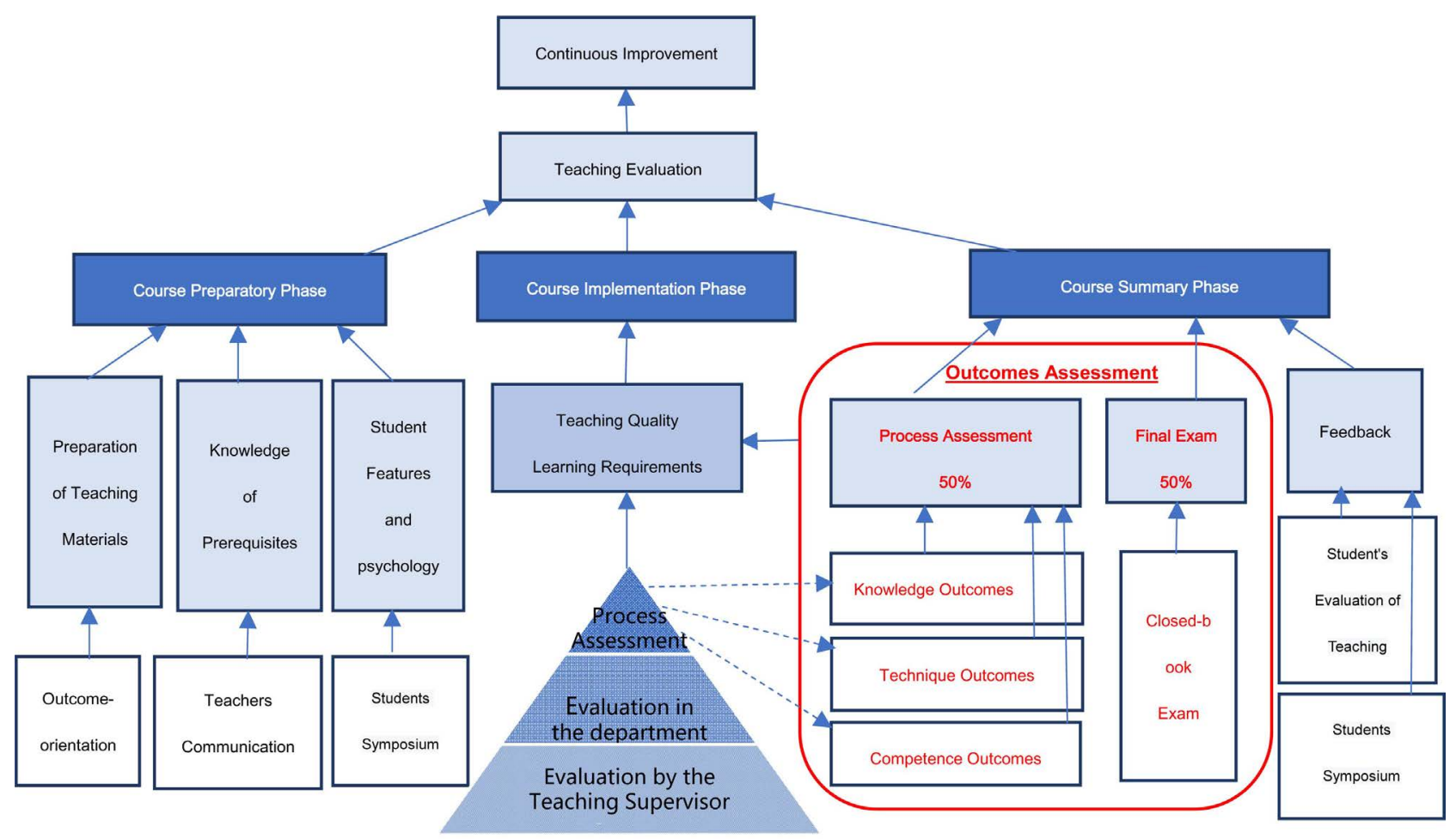

Figure 4. Three-stage teaching evaluation system based on the OBE. 
evaluation system-Three-stage Teaching Evaluation System Based on the OBE (Figure 4). The teaching quality and teaching effects should be evaluated step by step and comprehensively according to the preparation stage, implementation stage and summary stage of the course, and attention should be paid to listening to the evaluation feedback of multi-channels, so as to achieve continuous improvement and guide the next round of teaching.

\subsection{Enrich Bilingual Learning Resources}

In the Internet era, students attach importance to experience, interaction, individuality and convenience in their learning process. Teachers should understand the characteristics of bilingual teaching, fully analyze and evaluate the existing teaching resources and conditions, and effectively respond to the diversified and personalized learning needs of students. Efforts should be made to build online and offline complementary learning resources that combine theory and practice, give consideration to both commonness and individuality, and build open and three-dimensional learning space. The teaching process should fully reflect the student-centered teaching care, maintain the flexibility and vitality of teaching, and help students achieve the expected outcomes and objectives with the gradual and subtle teaching program. At the same time, colleges and universities should adhere to the internal and external interaction, and promote the construction of practical education base, enterprise training base and other practical teaching platforms.

\section{Conclusion}

The internationalized application-oriented talents are urgently needed in China. The objectives of the traditional talents cultivation model are ambiguous, and the training process is relatively rigid, which seriously deviate from the needs of economic and social development. The OBE model adheres to the student-centered, learning-oriented and aims at improving students' comprehensive practical ability. Bilingual teaching under the OBE model requires systematic design of students' expected learning outcomes, selection of teaching contents, design of teaching activities, design of assessment system and teaching evaluation system, as well as continuous enrichment of online and offline learning resources for bilingual teaching. The OBE model is of great significance to bilingual teaching practice, which can realize "student-centered" teaching and "outcome-based" learning, and establish an operational excellent mode for cultivating application-oriented talents in the field of international business and economics.

\section{Supporting Fund}

1) Bilingual Teaching Reform and Practice-Based on the Model of Outcome-based Education (ZD20200409, Key Project of Education and Teaching Reform and Research, Beijing Institute of Petrochemical Technology). 2) Study 
on the Emergency Linkage Mechanism and Policy of Beijing-Tianjin-Hebei Coordinated Response to Accidents and Disasters (18GLB020, 2018 Beijing Social Science Foundation Project).

\section{Conflicts of Interest}

The authors declare no conflicts of interest regarding the publication of this paper.

\section{References}

Amini, M. I., Takmil, F. R., Abiri, S. A. et al. (2014). The Use of the Dundee Three-Circle Model to Assess Quality of Medical Education. Medical Teacher, 1, 159-171. ttps://doi.org/10.3109/0142159X.2014.916789

Battistini, J. (1995). From Theory to Practice: Classroom Application of Outcome-Based Education. Academic Standards, 4, 111-126.

Jiang, B. (2003). OBE: Results-Based Education. Foreign Education Research, 3, 37-39.

Learning, S. (2010). Outcome-Based Education. Journal of Veterinary Medical Education, 3, 258-263.

Li, Z. (2014). Analysis of the Student Center Concept of Engineering Education Professional Certification. China Higher Education, 21, 19-22.

Wang, Q., Li, W., Li, R. et al. (2017). Discussion on Talent Training Model of Applied Logistics Engineering-Based on OBE. Journal of Heilongjiang Institute of Engineering, 2, 77-80.

Wang, Z. (2020). Research on Teaching Reform of Marketing Major Based on "Outcome-Oriented + Action Learning”. Vocational Technology, 1, 33-36.

$\mathrm{Wu}, \mathrm{Q}$. (2011). Several Issues to be Paid Attention to in the "Implementation of National Medium- and Long-term Program for Education Reform and Development (2010-2020)". Research on Education Development, 17, 68-71.

Yang, J., Liu, C., \& Peng, D. (2019). Research on Public Physical Education Curriculum Reform in Universities Under the Concept of Outcome-oriented Education-A Case Study of Southwest Petroleum University. Educational Theory and Practice, 6, 58-60.

Zambrano, C. (2020). Continuous Improvement Model to Systematize Curricular Processes in Engineering Education. Proceedings of the IEEE, 1, 1-7.

https://doi.org/10.1109/CHILECON47746.2019.8988093 